DOI: http://dx.doi.org/10.11606/issn.1984-4867.v25i1p231-258

\title{
Extensão Universitária em Turismo: a atuação das instituições públicas de educação superior do Brasil
}

\author{
Extensión Universitaria en Turismo: la actuación de las instituciones públicas de \\ educación Superior de Brasil
}

\section{University Extension in Tourism: actions performed by public education institutions in Brazil}

Rafaela Camara Malerba ${ }^{1}$

Mirian Rejowski ${ }^{2}$

\section{Resumo}

Pesquisa exploratório-descritiva, com o objetivo de demonstrar a atuação das universidades públicas brasileiras no que se refere à extensão universitária em turismo, a partir dos dados do Sistema de Informação e Gestão de Projetos - SIGProj - desenvolvido pelo Ministério da Educação - MEC. São descritas 114 ações extensionistas em Turismo, iniciadas de 2006 a 2011, em relação à evolução temporal, perfil institucional, áreas temáticas e modalidades. Por fim, discute-se a concepção de extensão dos coordenadores das ações vinculadas a cursos de Turismo. Os resultados mostram que diferentes instituições do Brasil apresentam práticas extensionistas com foco em turismo, em diferentes áreas temáticas e modalidades, destacando-se projetos, eventos e cursos. No que diz respeito à concepção de extensão dos coordenadores das ações, a pesquisa revela que os mesmos veem as ações extensionistas especialmente como formas de concretizar o compromisso social da Universidade, de promover melhorias na qualidade de vida das populações e de relacionar teoria e prática no ensino do Turismo.

Palavras-chave: Turismo. Educação superior. Extensão universitária. Instituições públicas. Brasil.

\section{Resumen}

Investigación exploratoria y descriptiva sobre la actuación de las instituciones públicas brasileñas con respecto a la extensión universitaria en Turismo. El estudio tiene como base

\footnotetext{
1 Mestre em Hospitalidade pela Universidade Anhembi Morumbi (UAM). Bacharel em Turismo pela Universidade de São Paulo (USP). Licenciada em Letras pela Pontifícia Universidade Católica de São Paulo (PUC-SP). Professora efetiva do Instituto Federal de São Paulo (IFSP). Brasil. E-mail: rafaelamalerba@gmail.com.

${ }^{2}$ Livre Docente em Teoria do Turismo e Lazer, Doutora e Mestre em Ciências da Comunicação, Bacharel em Turismo pela USP. Professora Titular do Mestrado em Hospitalidade da UAM. Professora colaboradora do Mestrado em Turismo da USP. Brasil. E-mail: mirwski@gmail.com.
} 
los datos del Sistema de Información y Gestión de Proyectos - SIGProj - desarrollado por el Ministerio de Educación - MEC. Son descritas 114 acciones extensionistas iniciadas entre 2006 y 2011 en relación a evolución, perfil institucional, área y modalidad. Finalmente, se discute el concepto de extensión según los coordinadores de las acciones realizadas en cursos superiores de Turismo. Los resultados muestran que diferentes instituciones en Brasil desarrollan actividades extensionistas en variadas áreas y modalidades, con énfasis en proyectos, eventos y cursos. Revelan también que los coordinadores entienden las acciones extensionistas como formas de lograr el compromiso social de la Universidad, de promover mejoras en la calidad de vida y de relacionar teoría y práctica

Palabras clave: Turismo. Educación Superior. Extensión Universitaria. Instituciones Públicas. Brasil.

\begin{abstract}
This work consists of an exploratory and descriptive research about university extension in Tourism, specifically in public education institutions in Brazil. It aims at demonstrating how Brazilian public higher education institutions perform extension actions in the area of Tourism, based on data from SIGPRoj, a system developed by the Brazilian Ministry of Education to manage teaching, research and extension actions of academic institutions. To achieve this proposition, this study describes 114 actions, developed from 2006 to 2011, according to SIGProj. It also discusses the action coordinators' conception of university extension. The results show that institutions of many states of the country perform extensionist activities in a great variety of thematic areas and modalities, notably projects, events and courses. It also reveals that coordinators understand these actions as a way to fulfill universities' commitment to provide social returns, to promote improvements in communities' quality of life and to link theory and practice.
\end{abstract}

Keywords: Tourism. Higher Education. University Extension. Public institutions. Brazil.

\title{
1. Introdução
}

O ensino superior em Turismo no Brasil teve origem na década de 1970. Naquele momento, observava-se o início de uma demanda do mercado de trabalho para profissionais da área, o que estimulou as Instituições de Ensino Superior - IES - públicas ou privadas a oferecer cursos de bacharelado em Turismo. Até 1996, a oferta desses cursos expandiu-se lentamente, somando 40 bacharelados em todo o país. Entretanto, desse ano até 2006, observou-se uma acelerada expansão, alcançando-se 302 bacharelados em Turismo em diferentes estados. Nos anos seguintes, porém, constatou-se uma diminuição na procura de vagas em cursos de Turismo, o que levou a uma readequação dessa oferta. Por um lado, muitas instituições 
privadas encerraram suas turmas, ampliando a oferta de cursos superiores tecnológicos, com duração mais curta. Por outro, as instituições públicas ampliaram a oferta de bacharelados em Turismo (ANSARAH; REJOWSKI, 1996; CARVALHO, 2008).

Nesse cenário, as pesquisas em Turismo também passaram por um processo de evolução e amadurecimento. As IES, especialmente as universidades, voltaram-se à discussão sobre a importância e os caminhos da pesquisa em Turismo no Brasil. Esse processo resultou, na década de 1990, na publicação do primeiro periódico científico em Turismo - a revista Turismo em Análise - e no fortalecimento da linha de pesquisa "Turismo e Lazer" do programa de Mestrado e Doutorado em Ciências da Comunicação da Universidade de São Paulo - USP (REJOWSKI, 2010). Em 1998, surgiu o Mestrado em Turismo e Hotelaria da Universidade do Vale do Itajaí - Univali, ao qual se seguiram, na década seguinte, outros programas no Brasil, como o mestrado de Hospitalidade da Universidade Anhembi Morumbi, em 2002.

Por sua vez, a extensão universitária em Turismo, de modo geral, tem recebido pouca atenção dos estudiosos da educação superior na área, tanto na bibliografia nacional, quanto na internacional. Em 2012, à época de realização desta pesquisa, o Banco de Teses da Capes não elencava resultados para a busca dos termos "extensão universitária" e "turismo", ao passo que para a expressão "extensão universitária" retornava links para 404 documentos com foco em diferentes áreas, como Educação, Saúde, Direito, Letras, entre outras, externando reflexões, especialmente, no âmbito das Instituições Públicas de Ensino Superior - IPES.

A educação superior em Turismo passa por um momento de amadurecimento, do qual surgem diversas inquietações, muitas vezes objetos de estudos acadêmicos que priorizam, em geral, o ensino e a pesquisa; a extensão ocupa um espaço restrito nas reflexões, ainda que seja elemento fundamental da Universidade. Na última década, porém, observa-se o aumento do número de trabalhos de eventos e artigos acadêmicos que se ocupam especificamente de experiências extensionistas na área de Turismo. Malerba, Landi e Rejowski (2011) buscaram identificar, por meio de uma pesquisa documental em artigos acadêmicos e trabalhos de eventos, ações de extensão universitária na área de Turismo realizadas em instituições brasileiras. Foram localizados 23 projetos e programas, entretanto, os textos que os abordam priorizam a descrição de práticas extensionistas pontuais, e raramente discutem suas 
metodologias e resultados ou analisam a situação atual da extensão em Turismo na educação superior. Vale citar também as obras de Shigunov Neto e Maciel (2002) e Barretto, Tamanini e Silva (2004) que contemplam, em suas reflexões, a tríade ensino, pesquisa e extensão e a importância das atividades práticas e da aproximação entre academia e mercado, universidade e sociedade.

No Brasil, desde 1987, o Fórum Nacional de Pró-Reitores das Universidades Públicas Brasileiras - Forproex - tem atuado no planejamento, na organização e na sistematização da extensão das IPES. Entre suas ações mais significativas, encontram-se o Plano Nacional de Extensão, elaborado entre 1997 e 1998 (FORPROEX, 2000) que institui conceitos sobre a extensão e prevê a organização e a sistematização de suas práticas no Brasil, especialmente no âmbito das instituições públicas. Em 2012, após a realização deste trabalho, o Forproex publicou a Política Nacional de Extensão Universitária, que reafirmou a importância da construção de um sistema de informações e indicadores (FORPREOX, 2012).

Em um primeiro momento, a sistematização da extensão em nível nacional ocorreu por meio do Sistema Nacional de Informações de Extensão - SIEX Brasil, aplicativo online criado em 2003 para registro e divulgação de ações extensionistas. Em 2006, o Ministério da Educação MEC - em parceria com o Forproex desenvolveu, a partir do SIEX, o Sistema de Informação e Gestão de Projetos - SIGProj, com a finalidade de atender à demanda de registro, gestão, monitoramento e avaliação da extensão (MEC, 2012). O SIGProj registra propostas, ações e atividades em quatro plataformas: Ensino, Extensão, Pesquisa e Assuntos estudantis. O MEC e as instituições interessadas vinculam seus editais ao sistema e, dessa forma, todas as etapas de elaboração, envio e aprovação das ações que concorrem a verbas ocorrem por meio dele. À época de realização desta pesquisa, em abril de 2012, o SIGProj contava com $17742^{3}$ registros de ações extensionistas desenvolvidas em instituições de todo o Brasil, sob diferentes modalidades, em diferentes áreas.

Diante desse contexto, vislumbrou-se a possibilidade de realizar uma investigação científica com o objetivo de demonstrar a atuação das universidades públicas brasileiras no que se refere à extensão universitária em Turismo, com base nos dados do SIGProj. Cabe esclarecer

\footnotetext{
${ }^{3}$ Em dezembro de 2013, a plataforma Extensão do SIGProj identificava 28.141 registros o que sugere uma expansão das ações extensionistas e/ou do alcance do sistema junto às IES.
} 
que, ainda que essa base de dados não abranja todas as instituições nem todo o universo de ações extensionistas realizadas, constitui a base mais abrangente disponível atualmente, sendo acessível à consulta pública pela internet.

Trata-se de um estudo exploratório-descritivo, na medida em que procura aprimorar ideias sobre o tema e quantificar e caracterizar as ações extensionistas da amostra selecionada, além de descrever detalhadamente algumas ações (DENCKER, 1998). Em relação aos procedimentos técnicos adotados, pode ser identificado como bibliográfico e documental e inclui a aplicação de questionário semiestruturado junto a coordenadores de ações extensionistas.

Este artigo discorre, portanto, sobre o estabelecimento da prática e da conceituação de extensão no Brasil e sobre sua organização na contemporaneidade, sobretudo no caso das instituições públicas. Trata dos desdobramentos das diferentes concepções de extensão universitária e apresenta alguns desafios para os estudiosos e extensionistas. Por fim, caracteriza as atividades extensionistas em Turismo registradas no SIGProj com início de 2006 a 2011 e discute a concepção de extensão dos coordenadores das ações extensionistas vinculadas a bacharelados em Turismo.

\section{Extensão Universitária no Brasil}

Segundo Rocha (2001), o extensionismo originou-se na Universidade Medieval, quando estudantes irradiavam os conhecimentos para a sociedade por meio da participação em ações de assistência à população carente e de apresentações públicas sobre o aprendizado feito, por exemplo. No século XIX, as novas demandas sociais geradas pela Revolução Industrial deram origem à Universidade Moderna, uma instituição preocupada com a prestação de serviços à comunidade. Nesse cenário, especialmente nas universidades inglesas, a extensão surgiu como forma de atuar na preparação técnica para o modo de produção industrial (SOUSA, 2011). Segundo Serrano (2008), as primeiras práticas extensionistas inglesas exemplificam o modelo de transmissão vertical de conhecimento, em que a Universidade se apresenta como detentora de um saber absoluto e superior, transmitido verticalmente, ignorando a cultura e o saber populares. Trata-se do primeiro de quatro momentos conceituais identificados por ela na 
história da extensão, juntamente com voluntarismo, ação sociocomunitária e modelo acadêmico institucional (SERRANO, 2008).

No século XIX, também na Inglaterra, surgiram as Universidades Populares, nas quais os estudantes tinham a oportunidade de aplicar conhecimentos e difundir concepções de educação, entendida como um ato de amor engajado em prol de uma sociedade mais justa (ROCHA, 2001). A extensão inglesa alcançou, alguns anos depois, as universidades americanas, em que se manifestou em atividades de prestação de serviços técnicos em áreas rurais e urbanas, de difusão técnico-científica, de cursos profissionalizantes, entre outros. Esse tipo de prática extensionista teve forte influência na América Latina, onde se procurou implantar uma extensão técnica vinculada a programas de desenvolvimento (NOGUEIRA, 2001; ROCHA, 2001).

A extensão na América Latina inspirou-se também no extensionismo praticado nas Universidades Populares e incorporado como bandeira dos movimentos estudantis no início do século XX, entre os quais o Movimento de Córdoba, na Argentina (ROCHA, 2001). A extensão concebida pelo Movimento de Córdoba exemplifica, conforme Serrano (2008), o momento do voluntarismo ou da ação voluntária sociocomunitária, isto é, práticas extensionistas que objetivam ações filantrópicas, com vínculos ideológicos, comprometida com mudanças sociais. O voluntarismo, por um lado, dá à extensão um caráter meramente político e ideológico, muitas vezes ignorando o método; porém, representa um avanço por sinalizar a necessidade de transformação social (SERRANO, 2008).

No que diz respeito à origem de práticas extensionistas no Brasil, pode-se citar como pioneira a experiência da Universidade Livre de São Paulo que, de 1914 a 1917, oferecia conferências abertas ao público. Os temas, porém, não eram relacionados às problemáticas sociais e políticas da época e, portanto, acabaram por não despertar tanto interesse das classes populares (SOUSA, 2010; CARBONARI, PEREIRA, 2007; GURGEL, 1986). A partir da década de 1930, uma concepção de extensão institucionalizada e legalizada começou a se delinear no país. O termo foi utilizado pela primeira vez na legislação no Decreto-Lei n. 19.851 de 1931, que estabelecia o Primeiro Estatuto das Universidades Brasileiras (SOUSA, 2010). 
Na década de 1960, ainda que a LDB contemplasse apenas brevemente os cursos de extensão, a prática extensionista passou a se preocupar não tanto com a difusão do conhecimento, mas com a busca de ações que contribuíssem para a transformação social do país, por meio da inserção da universidade na realidade socioeconômica, política e cultural do país (CARBONARI; PEREIRA, 2007). No Brasil, a partir do Golpe de 1964, o governo iniciou o combate ao movimento estudantil e se apropriou de algumas ações dos estudantes como forma de envolvê-los em ações assistencialistas vinculadas aos ideais de Desenvolvimento e Segurança nacionais. É o caso do Projeto Rondon e do Centro Rural Universitário de Treinamento e Ação Comunitária - Crutac (NOGUEIRA, 2001). Segundo Serrano (2008), tais ações são os principais expoentes do momento da ação sociocomunitária institucional, estabelecido no contexto das décadas de 1960 e 1970, quando o movimento estudantil e a extensão universitária eram vistos como um risco ao regime militar; para evitá-lo, a prática extensionista sócio-comunitária não era sistemática nem sistêmica, e não possibilitava aos estudantes conhecer e relacionar-se em profundidade com a realidade trabalhada (SERRANO, 2008, p. 8).

Em 1968, a Reforma Universitária restringiu as ações das IES e impediu sua autonomia, rompendo com a concepção de extensão como diálogo com a comunidade (CARBONARI; PEREIRA, 2007). O documento legalizou a indissociabilidade entre ensino e pesquisa, porém a extensão foi citada apenas de forma indireta abordando suas duas vertentes mais presentes no Brasil: a europeia, voltada à oferta de cursos, e a americana, que prioriza a prestação de serviços (NOGUEIRA, 2001). Paralelamente, entre os anos 1960 e 1970, intelectuais e educadores de diferentes países da América Latina retomaram a discussão sobre o papel da extensão universitária como missão social (ROCHA, 2001). Ainda em 1968, Paulo Freire, em exílio no Chile, publicou Extensão ou comunicação. Na obra, o autor alertava para os pressupostos embutidos na palavra extensão, que deveria ser substituída por um termo que enfatizasse a comunicação (BOTOMÉ, 2001). Freire se preocupava com o caráter invasivo da prática extensionista como uma falsa ação educativa, já que não provocava mudanças, mas apenas transmitia, estendia os saberes universitários àqueles considerados menos favorecidos. Para eliminar tal equívoco, ele defendia uma mudança conceitual e terminológica de extensão 
para comunicação, já que esta ocorre mediante um diálogo entre dois sujeitos pensantes e ativos (FREIRE, 1983).

Na década de 1970, o Conselho dos Reitores das Universidades Brasileiras - CRUB elaborou as Diretrizes da Extensão Universitária, defendendo que a Universidade deveria ter interligadas as suas funções de ensino, pesquisa e extensão. Em 1975, o MEC criou a Coordenação de Atividades de Extensão e elaborou o Plano de Trabalho Nacional de Extensão que assegurava a este Ministério a competência de propor a política de extensão brasileira (NOGUEIRA, 2001).

A partir da década de 1980, com o fim das ditaduras, fortaleceram-se os movimentos sociais, e os responsáveis pela extensão universitária passaram a cobrar do governo federal apoio financeiro e autonomia para criar programas, projetos e ações condizentes com as realidades específicas de cada instituição. Nesse período, observaram-se experiências extensionistas variadas, mas ainda voltadas principalmente à prestação de serviços (ROCHA, 2001). Na América Latina, o final desta década e os anos 1990 foram marcados pela realização de encontros de docentes universitários. No Brasil, o fato mais marcante foi a criação do Forproex em 1987 (ROCHA, 2001). Desde então, a entidade tem atuado na interlocução com os órgãos governamentais, na elaboração de planos e programas nacionais de extensão, na realização de eventos e na publicação de cadernos e estudos e na estruturação da Rede Nacional de Extensão - Renex, que mantém cadastro atualizado das instituições integrantes e divulga ações extensionistas universitárias (RENEX, 2011). Segundo Serrano (2008), a criação do Forproex marca o momento acadêmico institucional no panorama da extensão no Brasil: desmistifica-se a extensão como militância política, iniciando a discussão sobre a indissociabilidade entre os fazeres acadêmicos. A extensão passa a ser vista, assim, como uma via de mão dupla e conhecimento que proporciona uma relação transformadora entre Universidade e sociedade (SERRANO, 2008).

Em 1987, durante o I Encontro Nacional de Pró-Reitores de Extensão das Universidades Públicas Brasileiras, elaborou-se um conceito de extensão universitária que deveria orientar a prática, especialmente, das universidades públicas: 
A extensão universitária é um processo educativo, cultural e científico, que se articula ao ensino e à pesquisa de forma indissociável, e que viabiliza a relação transformadora entre a Universidade e a sociedade. A extensão é uma via de mão dupla, com trânsito assegurado à comunidade acadêmica, que encontrará, na sociedade, a oportunidade da elaboração da práxis de um conhecimento acadêmico. No retorno à universidade, docentes e discentes trarão um aprendizado que, submetido à reflexão teórica, será acrescido àquele conhecimento. Este fluxo, que estabelece a troca de saberes sistematizados - acadêmico e popular, terá como consequência - a produção de conhecimento resultante do confronto com a realidade brasileira e regional; e a democratização do conhecimento acadêmico e a participação efetiva da comunidade na atuação da universidade. Além de instrumentalizadora deste processo dialético de teoria/prática, a Extensão é um trabalho interdisciplinar que favorece a visão integrada do social (FORPROEX, 2000, p.5).

Conforme Nogueira (2001), este conceito supera as concepções de extensão como mera transmissão de conhecimentos e atividade assistencialista isolada do ensino e da pesquisa; a ideia de tripé - três funções isoladas - dá lugar à visão do trabalho acadêmico como um processo orgânico, contínuo e coletivo. Pode-se dizer que se pressupõe não mais a soma, mas a articulação entre ensino, pesquisa e extensão.

Se no âmbito acadêmico ampliava-se o conceito de extensão, a legislação brasileira não seguia no mesmo sentido, restringindo-se a concepções do início do século e tratando a extensão com superficialidade (NOGUEIRA, 2001). A LDB de 1996, por exemplo, retoma a ideia de extensão como derramamento de saber ao se referir à extensão como forma de difusão das conquistas e benefícios da criação cultural e da pesquisa universitária (BRASIL, 1996). O Plano Plurianual 2000-2003, por sua vez, define como objetivos do Programa Nacional de Extensão Universitária a promoção do aperfeiçoamento dos alunos universitários e a prestação de serviços sociocomunitários (BRASIL, 1999). O documento reconhece a possibilidade de diálogo ao prever o aprendizado por parte dos estudantes, porém de forma restrita à prestação de serviços.

Cunha (2010) ressalva que a LDB de 1996 admitiu a existência de ensino superior sem pesquisa, que só seria obrigatória para as universidades, o que significa uma regressão na concepção de educação superior. Por outro lado, a Constituição determinava a indissociabilidade entre ensino, pesquisa e extensão, mas não se viam esforços que possibilitassem tal integração. Cunha (2010) destaca, inclusive, que a própria estrutura de 
funcionamento dos órgãos federais relacionados à educação superior provocou uma dicotomia no vínculo das universidades com o MEC, uma vez que a graduação é supervisionada pela Secretaria de Educação Superior - SESU -, e a pós-graduação pela CAPES. Essa condição, segundo a autora, reforçaria a ideia de que pesquisa é tarefa da pós-graduação, e o ensino caracteriza a graduação. A extensão, por sua vez, estaria à margem desse processo, com frágil regulação e pouco financiamento. Para Nogueira (2001), do ponto de vista governamental situam-se duas concepções: aquela em que a extensão é tida como prática assistencialista que substitui as funções do Estado e aquela em que se desenvolve como prestação de serviços dirigida a um público que pode pagar por elas, favorecendo a arrecadação de recursos para as instituições de ensino.

Entre 1997 e 1998, o Forproex elaborou o Plano Nacional de Extensão Universitária, com o intuito de orientar o desenvolvimento da atividade, sem pretender, entretanto, interferir na autonomia das universidades no que diz respeito ao desenvolvimento de seus programas extensionistas (FORPROEX, 2000). O Plano reitera o conceito de extensão elaborado em 1987 e apresenta objetivos e metas para a extensão universitária, entendida como ação capaz de imprimir um novo rumo à Universidade brasileira. Segundo este documento, as atividades de pesquisa, ensino e extensão deveriam ocorrer de maneira tão integrada, que fosse desnecessário distinguir uma da outra. O Plano apresenta onze objetivos que, em linhas gerais, buscam reafirmar a importância da extensão como processo acadêmico; garantir o diálogo entre a sociedade e a Universidade; valorizar ações de extensão multi, inter e/ou transdisciplinares, bem como interinstitucionais, e priorizar práticas que atendam necessidades sociais emergentes. Para Serrano (2008), o plano ressignifica a extensão universitária numa perspectiva cidadã que permite pensar em três funções da Universidade: acadêmica, fundamentada em bases teórico-metodológicas; social, promotora da organização social e da construção da cidadania, e articuladora do saber e do fazer e da Universidade com a sociedade.

Segundo Sousa (2010), embora a extensão universitária tenha sofrido por parte do Estado uma construção lenta e pouca ousada de sua concepção, a criação do Forproex ocasionou uma maior atenção às questões da extensão por parte do MEC. Dessa forma, nota-se na atualidade 
uma predisposição por parte do Ministério e das IES em trabalhar juntos e um avanço na construção da concepção de extensão.

Em maio de 2012, durante o XXXI Encontro Nacional do Forproex, aprovou-se a Política Nacional de Extensão Universitária, fruto de discussões da entidade e de seus membros desde 2009 (FORPROEX, 2012). De modo geral, a Política reitera as diretrizes construídas historicamente e coloca em discussão novas preocupações e desafios, especialmente no que tange à avaliação e ao monitoramento da extensão, às parcerias institucionais e ao papel da Universidade como instrumento de mudança social. Dessa forma, outro conceito de extensão é proposto pelo documento:

A Extensão Universitária, sob o princípio constitucional da indissociabilidade entre ensino, pesquisa e extensão, é um processo interdisciplinar, educativo, cultural, científico e político que promove a interação transformadora entre Universidade e outros setores da sociedade (FORPROEX, 2012, p.15).

Como princípios da extensão, o documento enfatiza a interação dialógica entre Universidade e sociedade, a interdisciplinaridade e interprofissionalidade, a indissociabilidade ensinopesquisa-extensão, o impacto na formação do estudante, e o impacto e a transformação social. Uma preocupação histórica do Forproex reafirmada pela Política diz respeito à organização e a sistematização da extensão nas diferentes instituições, especialmente para possibilitar a avaliação das práticas extensionistas. Nesse sentido, desde 2001, têm-se proposto algumas padronizações e critérios para classificação das ações como Modalidades, Áreas Temáticas e Linhas de Extensão. Em relação à modalidade, as ações podem constituir programas, projetos, cursos, eventos e prestações de serviço (FORPROEX, 2007a). Além disso, cada ação pode ser classificada em uma ou duas das oito áreas temáticas pré-definidas: Comunicação, Cultura, Direitos Humanos e Justiça, Educação, Meio Ambiente, Saúde, Tecnologia e Produção, Trabalho. As linhas de extensão, por sua vez, relacionam-se a diferentes áreas temáticas, ou seja, uma mesma linha pode estar vinculada a ações extensionistas de diferentes áreas (FORPROEX, 2007; FORPROEX, 2013). Como exemplos de linhas podem ser citadas: alfabetização, leitura e escrita; direitos individuais e coletivos; patrimônio cultural, histórico e 
natural; desenvolvimento regional; desenvolvimento urbano. Para cada linha de extensão, o Forproex apresenta as formas de operacionalização mais frequentes. A linha Turismo é assim descrita:

Planejamento e implementação do turismo (ecológico, cultural, de lazer, de negócios, religioso, etc.) como setor gerador de emprego e renda; desenvolvimento de novas tecnologias para avaliações de potencial turístico; produção e divulgação de imagens em acordo com as especificidades culturais das populações locais (FORPROEX, 2007a).

Cabe destacar que, em razão da natureza interdisciplinar do turismo, é possível que as ações extensionistas desta área possam estar relacionadas também a outras linhas, como Educação profissional, Artes integradas, Desenvolvimento regional, Desenvolvimento urbano, Terceira idade, Esporte e lazer, Patrimônio histórico natural e cultural, entre outros.

A despeito da representatividade e da atuação do Forproex junto ao MEC e às universidades públicas, a instituição não é o único fórum de extensão no Brasil. Suas deliberações e ações tampouco são unanimidade entre dirigentes de IES particulares, comunitárias e mesmo públicas. As críticas advindas das universidades particulares e comunitárias referem-se à falta de espaço e ao não reconhecimento por parte do Forproex. Tais instituições congregam-se, respectivamente, sob o Fórum de Extensão das Instituições de Ensino Particulares - Forexp, criado em maio de 2003, e o Fórum Nacional de Extensão e Ação Comunitária das Universidades e Instituições de Ensino Superior Comunitárias - Forext, criado em outubro de 1999 (OLIVEIRA, 2006; SOUZA, BORTOLINI, NODARI, 2007). Segundo Rocha (2006), essas instituições questionam o Forproex desde o lançamento do Plano que teria sido feito "pelas universidades públicas para as universidades públicas", ao que o Forproex responde afirmando ser necessário às IPES um espaço próprio para discussão de sua agenda. Evidentemente, essas críticas não alteram a importância do Forproex como entidade que pensa, planeja e organiza a extensão universitária, mas sinalizam possíveis fragilidades que atenuam a abrangência da representatividade desse fórum.

Nas primeiras décadas do século XXI, alguns dilemas envolvem as discussões e práticas relacionadas à extensão universitária. Segundo Botomé (1996), um grande desafio reside no 
entendimento da extensão como forma de concretizar o compromisso social da Universidade. Para ele, tal entendimento é equivocado, uma vez que "[...] a função de qualquer instituição social é melhorar a qualidade de vida de todos na sociedade" (BOTOMÉ, 1996, p.77) e a missão da Universidade seria, dessa forma, produzir conhecimento e torná-lo acessível. Podese dizer, portanto, que procurar relação entre Universidade e sociedade é uma proposta redundante, originária da visão de instituições de ensino fechadas em si mesmas.

Outro dilema diz respeito à concepção equivocada de pesquisa, ensino e extensão como um tripé, em que cada pilar tem um fim em si mesmo, ao invés de um sistema articulado. A imagem do tripé ocasionaria, inclusive, distinções equivocadas entre os docentes das Universidades: de um lado estariam os aptos para a pesquisa, e de outro, os que se dedicam à extensão. Aqueles veem os extensionistas como pares a quem falta competência para a pesquisa, e estes entendem os pesquisadores como representantes de um ensino degenerado e de uma pesquisa sem propósito (VALÊNCIO, 2000). Cunha (1998) destaca que a maneira como o currículo é trabalhado nas Universidades dificulta a integração entre ensino, pesquisa e extensão, pois é organizado sob uma ótica positivista e linear baseada na premissa de que o aprendiz deve primeiro dominar a teoria para entender e atuar na realidade. Nessa concepção, a extensão seria entendida como a aplicação da pesquisa e do ensino (CUNHA, 2010). Tratase, porém, de uma visão errônea, pois é da prática que nasce o questionamento, mola propulsora para a pesquisa. A extensão universitária, ao possibilitar o encontro do aluno com a realidade, seria, portanto, fonte inesgotável de questionamentos que poderia fazê-lo ressignificar as experiências de sala de aula e, possivelmente, o impulsionariam para a pesquisa, isto é, a busca pelas respostas.

A operacionalização das ações extensionistas, especialmente sua metodologia, também tem constituído um desafio. Segundo Thiollent (2008), na década de 1990, não havia clareza das atividades e modalidades de extensão, tampouco recursos financeiros específicos, nem avaliação sistematizada. No final da década de 2000, a situação da extensão ainda não teria se equiparado ao ensino e à pesquisa, mas já teria melhorado bastante. Com uma visão mais pragmática, o autor destaca a importância de discutir a metodologia dos projetos de extensão, de forma a definir ações dentro do alcance de seus executores. Para ele, o excesso de vinculação política dos projetos poderia prejudicar a produção e distribuição de um 
conhecimento bem embasado, uma vez que as teorias e metodologias seriam substituídas por um discurso político. Thiollent (2008) ressalta também a necessidade de se refletir sobre a ética nos projetos de extensão, especialmente em relação às formas de engajamento dos participantes, às expectativas criadas na população e à diversidade cultural.

\section{Extensão em Turismo das Universidades Públicas no Brasil de 2006 a 2011}

\subsection{Metodologia}

A fim de compreender a realidade da extensão universitária em Turismo nas instituições públicas de ensino superior, realizou-se pesquisa documental na plataforma Extensão da base de dados do SIGProj. As ações extensionistas foram identificadas a partir do formulário para consulta pública, tendo como filtro as palavras-chave turismo, turista $(s)$, turístico $(s)$, turística $(s)$, turismólogo(s), turismóloga $(s)$ ou turismologia. Essa busca identificou 114 ações realizadas em diferentes instituições de ensino do Brasil de 1006 a 2011. As informações disponíveis no SIGProj propiciaram a construção de um banco de dados eletrônico, a partir do qual as ações foram caracterizadas em relação a: a) evolução temporal; b) instituição; c) localização; d) unidade responsável; e) área temática; f) modalidade; g) duração; h) públicoalvo.

Além disso, tendo em vista compreender especialmente a realidade da extensão desenvolvida no âmbito dos bacharelados de Turismo, foram aplicados questionários semiestruturados junto aos coordenadores de ações vinculadas a estes cursos. Para identificá-las, verificou-se o vínculo do coordenador de cada ação com bacharelados de Turismo à época de sua realização, conforme consulta à plataforma Lattes e ao site da instituiçãos.

Das 114 ações iniciais, identificaram-se 53 ações coordenadas por 34 docentes vinculados a bacharelados em Turismo. Os questionários semi-estruturados foram anexados à mensagem

\footnotetext{
${ }^{4}$ Em dezembro de 2013, uma busca com os mesmos parâmetros retornou 204 registros.

${ }^{5}$ Cabe ressalvar que o campo "Unidade de Origem" não seria suficiente para este identificação, pois muitas vezes citava a diretoria do campus ou o órgão responsável pela extensão; além disso, em alguns casos, apresentava-se em branco.
} 
de correio eletrônico enviada aos coordenadores, dos quais 17, responsáveis por 29 ações, responderam.

As respostas foram organizadas e sistematizadas em banco de dados eletrônico, e a análise e a interpretação realizaram-se em três etapas: a) verificação de temas emergentes nas respostas dadas a cada pergunta do questionário, tendo em vista identificar os mais recorrentes e, a partir daí, agrupar os posicionamentos semelhantes; b) seleção das afirmações centrais de cada resposta que ilustram os diferentes posicionamentos identificados previamente; c) identificação de termos e expressões do discurso teórico presentes nas respostas dos coordenadores, a fim de verificar o pressuposto conceitual presente em suas afirmações e posicionamentos e propiciar o diálogo com os teóricos.

Como produto final, a descrição da concepção de extensão pelos coordenadores agrupa e exemplifica os posicionamentos, reconstrói o sentido geral de cada grupo de respostas e dialoga com a teoria acerca dos temas abordados. Na apresentação dos resultados, a identificação dos respondentes foi mantida em anonimato, e as respostas transcritas literalmente em itálico.

\subsection{Caracterização das ações}

O número de ações extensionistas em Turismo registradas no SIGProj de 2006 a 2011 apresenta um movimento ascendente: 2 ações em 2006; 6 em 2007; 7 em 2008; 18 em 2009; 38 em 2012, e 43 em 2011 (considerando-se o ano de início informado). Esse crescimento reflete, possivelmente, a maior adesão das instituições ao sistema a partir de sua implantação, o que é evidenciado pelo número de editais cadastrados a cada ano: 2006, 4 editais; 2007, 7; 2008, 34; 2009, 42; 2010, 46; 2011, 60 editais. Observa-se, porém, que o crescimento do número de editais foi de $1.400 \%$, ao passo que, de 2006 a 2011, o número de ações em Turismo aumentou em $2.050 \%$.

Das 114 ações extensionistas identificadas, $97(85,1 \%)$ vinculam-se a 20 universidades públicas estaduais ou federais, e $17(14,9 \%)$ a um instituto federal, especificamente o Instituto Federal de Educação, Ciência e Tecnologia do Rio Grande do Sul - IFRS. Dessas 21 instituições, 12 sediam cursos de bacharelado em Turismo, embora nem sempre, nesses casos, as ações extensionistas identificadas sejam a eles vinculadas. Cabe destacar que o IFRS não 
oferece bacharelado na área em Turismo, porém sedia um curso técnico em Guia de Turismo no campus de Restinga. Da mesma forma, a Universidade Federal de Santa Maria oferece o curso superior de Tecnologia em Gestão de Turismo.

Das 21 instituições identificadas, 17 são federais e apenas 3 estaduais. Como reflexo desta distribuição, 70,6\% das ações são vinculadas a instituições federais e 20,18\%, a universidades estaduais. A tabela 1 apresenta a distribuição das ações SIGProj conforme a instituição e a presença ou não de bacharelado em Turismo.

\begin{tabular}{|c|c|c|c|c|}
\hline Região & $\mathbf{U F}$ & Instituição & $\begin{array}{l}\text { Bacharelado em } \\
\text { Turismo? }\end{array}$ & Ações \\
\hline \multirow{5}{*}{$\mathrm{CO}$} & DF & Universidade de Brasília - UnB & Sim & 6 \\
\hline & \multirow{2}{*}{ MS } & Universidade Estadual de Mato Grosso do Sul - UEMS & Sim & 16 \\
\hline & & Universidade Federal de Mato Grosso do Sul - UFMS & Sim & 22 \\
\hline & \multirow{2}{*}{ MT } & Universidade Federal de Mato Grosso - UFMT & Não & 4 \\
\hline & & Universidade do Estado de Mato Grosso - UNEMAT & Sim & 1 \\
\hline \multirow{5}{*}{$\mathrm{NE}$} & $\mathrm{BA}$ & Universidade Federal do Recôncavo da Bahia - UFRB & Não & 1 \\
\hline & MA & Universidade Federal do Maranhão - UFMA & Sim & 2 \\
\hline & $\mathrm{PB}$ & Universidade Federal da Paraíba - UFPB & Sim & 10 \\
\hline & $\mathrm{PE}$ & Universidade Federal de Pernambuco - UFPE & Sim & 2 \\
\hline & PI & Universidade Federal do Piauí - UFPI & Sim & 2 \\
\hline \multirow{4}{*}{$\mathrm{N}$} & AM & Universidade Federal do Amazonas - UFAM & Não & 2 \\
\hline & \multirow{2}{*}{ PA } & Universidade Federal do Oeste do Pará - UFOPA & Não & 1 \\
\hline & & Universidade Federal do Pará - UFPA & Sim & 1 \\
\hline & RR & Universidade Federal de Roraima - UFRR & Não & 1 \\
\hline \multirow{3}{*}{ SE } & \multirow{2}{*}{ MG } & Universidade Federal de Minas Gerais - UFMG & Sim & 1 \\
\hline & & Universidade Federal de São João Del Rey - UFSJ & Não & 1 \\
\hline & RJ & Universidade Federal Fluminense - UFF & Sim & 14 \\
\hline \multirow{4}{*}{$\mathrm{S}$} & \multirow{3}{*}{$\mathrm{RS}$} & Universidade Federal do Rio Grande - FURG & Sim & 5 \\
\hline & & $\begin{array}{l}\text { Instituto Federal de Educação, Ciência e Tecnologia do } \\
\text { Rio Grande do Sul - IFRS }\end{array}$ & Não & 17 \\
\hline & & Universidade Federal de Santa Maria - UFSM & Não & 1 \\
\hline & $\mathrm{SC}$ & Universidade do Estado de Santa Catarina - UDESC & Não & 4 \\
\hline Total & & & & 114 \\
\hline
\end{tabular}

Tabela 1 - Universidades das ações extensionistas em Turismo do SIGProj - Brasil, 2006-2011 Fonte: Elaboração própria com base em dados do SIGProj, (MEC, 2012). 
Observa-se que a maioria das ações extensionistas em Turismo cadastradas no SIGProj foram realizadas por instituições localizadas na região Centro-Oeste, com destaque para a UEMS $(14,67 \%)$ e a UFMS (20,18\%), ambas no Mato Grosso do Sul (tabela 2). Essa concentração pode estar relacionada à origem do SIEX, que foi desenvolvido pela UFMS em parceria com o Forproex. Entretanto, para confirmar ou rejeitar esta possibilidade, haveria necessidade de pesquisas sobre o desenvolvimento das ações nessas e em outras instituições, inseridas ou não no SIGProj.

\begin{tabular}{lcr}
\hline Região & Ações & \% \\
\hline Centro-Oeste & 49 & $42,98 \%$ \\
\hline Sul & 27 & $23,68 \%$ \\
\hline Nordeste & 17 & $14,91 \%$ \\
\hline Sudeste & 16 & $14,04 \%$ \\
\hline Norte & 5 & $4,39 \%$ \\
\hline Total & $\mathbf{1 1 4}$ & $\mathbf{1 0 0 \%}$ \\
\hline
\end{tabular}

Tabela 2 - Distribuição regional das universidades responsáveis pelas ações extensionistas em Turismo do SIGProj - Brasil, 2006-2011

Fonte: Elaboração própria com base em dados do SIGProj (MEC, 2012).

Em contrapartida, a região Norte apresenta apenas 4,59\% dos registros identificados. É interessante notar também que a região Sudeste, a despeito de ser a pioneira da Educação Superior em Turismo no Brasil e concentrar a maioria dos bacharelados na área, tanto em instituições públicas quanto privadas, representa apenas $12,84 \%$ das ações cadastradas junto ao SIGProj. Cabe destacar inclusive que não foi identificado nenhum registro em instituições do estado de São Paulo tendo como palavra-chave termos derivados de turismo. Isso pode se relacionar ao fato que, entre os cursos ofertados em universidades públicas do estado, dois serem da USP, uma instituição estadual pouco inserida no SIGProj e com sistema próprio de sistematização de suas práticas extensionistas, como também é o caso da Universidade Federal de São Carlos - UFSCar - e da Universidade Estadual Paulista Júlio de Mesquita Filho - Unesp.

Ressalva-se que, por apresentar apenas as ações de instituições que vinculam seus editais de extensão ao sistema, o SIGProj não reflete necessariamente a distribuição das ações extensionistas em Turismo nas instituições públicas brasileiras, já que muitas delas possuem seus próprios sistemas de cadastro e gerenciamento de ações de extensão. A esse respeito, convém citar os resultados do levantamento preliminar realizado por Malerba, Landi e 
Rejowski (2011) com o objetivo de identificar ações extensionistas em Turismo. A partir de artigos de periódicos e trabalhos de eventos, as autoras identificaram 23 ações desenvolvidas entre 2000 e 2010, sendo 9 em instituições privadas e 14 em instituições públicas, algumas das quais não aparecem nas ações identificadas a partir do SIGProj: Universidade Estadual do Mato Grosso do Sul - UEMS; Universidade Federal do Maranhão - UFMA; Pontifícia Universidade Católica de Minas Gerais (PUC/MG); Centro Universitário Newton Paiva; Universidade Federal do Rio de Janeiro - UFRJ; Universidade Federal de Campina Grande UFCG; Universidade Fumec; Instituto Federal de Educação Ciência e Tecnologia de Minas Gerais - IFMG; Universidade Estadual Paulista Júlio de Mesquita Filho- Unesp; Universidade de São Paulo - USP, Associação Educacional de Garça; Universidade Federal do Paraná - UFPR, e Universidade do Vale do Itajaí - Univali.

Além da instituição, as ações registradas no SIGProj são identificadas também pela Unidade Geral - campus, pró-reitoria, faculdade, centro ou instituto - e pela Unidade de Origem departamento, curso ou diretoria - à qual se vinculam. Das 114 ações, 8,77\% não identificaram a unidade geral e a unidade de origem; 20,18\% se relacionam ao órgão responsável pela extensão na Instituição e 6,14\% à diretoria do campus. A maioria das ações (40,35\%) vincula-se ao departamento ou coordenação responsável pelo curso de Turismo, porém é notável o fato de $24,56 \%$ das ações serem vinculadas a departamentos e centros que não abrigam cursos de Turismo, o que evidencia as contribuições de variadas áreas e disciplinas para esse campo de conhecimento, como destacam Rejowski (1996), Tribe (1997), Panosso Netto (2011) e Jafari (2005). As ações vinculadas a outros departamentos, em geral, estão abrigadas em unidades de Ciências Humanas e Sociais - como Letras, Geografia, Antropologia, História, Educação, Economia.

O mecanismo de consulta pública do SIGProj permitiu também a identificação da Área Temática de cada ação extensionista selecionada, conforme a classificação proposta pelo Forproex. As áreas de Tecnologia e Produção (25,44\%), Direitos Humanos e Justiça (23,68\%) e Cultura $(22,81 \%)$ são as que mais se destacam o que, de certa forma, reflete a orientação das unidades de origem dos projetos, em especial nas Ciências Humanas e Sociais. A área temática de Meio Ambiente é representada por apenas uma ação, ainda que vários projetos abordem temáticas de Turismo e Meio Ambiente, Ecoturismo e Educação Ambiental. Chama 
atenção também o fato de a área Trabalho responder por apenas 14,04\% das ações, uma vez que se trata da única área que apresenta um subtema diretamente relacionado ao turismo, qual seja, turismo e oportunidades de trabalho. Cita-se que não há nenhuma ação relacionada à área temática de Educação entre todos os registros identificados. Comunicação e Saúde respondem, respectivamente, por $7,02 \%$ e $6,14 \%$ das ações.

A diversidade de áreas temáticas ilustra a pluralidade de olhares envolvidos no estudo do Turismo como campo de conhecimento e reflete a variedade de dimensões do turismo como soma de fenômenos e relações originados da interação entre as regiões e localidades geradoras de fluxo e hospedeiras, os turistas, as empresas do setor, os governos e às comunidades (TRIBE, 2008; REJOWSKI, 1996).

No que diz respeito à modalidade das ações extensionistas identificadas, observa-se a predominância dos projetos, com 63 registros $(57,8 \%)$, seguidos por 25 eventos $(22,94 \%), 15$ cursos $(13,76 \%), 4$ programas $(3,67 \%)$ e 2 prestações de serviços. Os programas, possivelmente por sua natureza mais complexa e por demandarem mais recursos físicos e financeiros, correspondem a uma parcela pequena das ações identificadas. Tal fato pode ser consequência também das disposições dos editais cadastrados no SIGProj, da indisponibilidade de verbas para ações de médio ou longo prazo ou do baixo interesse das instituições. A baixa ocorrência de programas pode revelar também a pouca articulação entre ações de extensão, pesquisa e ensino com objetivos comuns. De qualquer forma, para uma compreensão acurada desse quadro, novas investigações se fazem necessárias.

As prestações de serviços mostraram-se também pouco representativas, o que pode sinalizar, eventualmente, dificuldades para realização de parcerias e contratações entre instituições, comunidades, empresas e órgãos públicos - hipótese que demanda novas investigações para sua confirmação. Cabe destacar, por outro lado, entre os projetos vinculados a cursos de Turismo, ações que poderiam configurar-se como prestações de serviço, pois correspondem a trabalhos oferecidos a comunidades e organizações.

A duração das ações varia de um dia a dois anos, o que pode ser explicado em razão das diferentes modalidades. Os 66 projetos - modalidade mais frequente - apresentam duração de 26 a 751 dias, sendo a média 315 dias. Desses, 54,55\% apresentam duração entre seis meses a 
um ano; $24,24 \%$ de mais de um ano a um ano e meio; $13,64 \%$, menos de seis meses, e 7,58\% de dois anos ou mais. Note-se que $86,37 \%$ dos projetos apresentam duração superior a seis meses. As duas prestações de serviço têm duração de 238 e 367 dias. Os quatro programas apresentam duração de 145 a 365 dias, contradizendo os critérios para caracterização desta modalidade, que pressupõe execução em médio ou longo prazo (FORPROEX, 2007a). Os 14 cursos tem duração entre 5 e 227 dias, sendo a média 95 dias. Os eventos, por sua vez, apresentam duração de 1 a 365 dias, com média de 103 dias. Supõe-se, dessa forma, que duração dos eventos contempla não apenas a realização do evento em si, mas também etapas de planejamento e pós-evento.

Em relação ao público alvo das ações extensionistas, 83,3\% delas focam o público externo, procurando atingir acadêmicos, estudantes do ensino básico, profissionais e instituições do setor e comunidades específicas. Além disso, 56,1\% das ações objetivam também o público interno, representado, em geral, por graduandos de Turismo e outras áreas. Cabe citar que $43 \%$ das ações procuram atingir segmentos de ambos os públicos, por outro lado, $13,1 \%$ das ações focam apenas o público interno. Tal resultado causa surpresa, uma vez que se entende extensão universitária como o processo educativo, cultural e científico que viabiliza uma relação transformadora entre a Universidade e a sociedade. Logo, pressupõe-se que ações extensionistas deveriam ter o intuito de possibilitar o diálogo entre comunidade interna e externa das instituições, ao invés de contemplar a Universidade voltada a ela mesma.

\subsection{Concepção de extensão}

A motivação dos coordenadores respondentes para coordenar e realizar ações extensionistas envolve, primordialmente, fatores pessoais, demandas da atividade docente universitária ou comprometimento com a comunidade. Sete coordenadores indicaram especificamente necessidades dos alunos como fatores motivacionais, especialmente no que diz respeito à integração com o mercado de trabalho e com a comunidade, e o desenvolvimento de olhar crítico sobre a realidade.

Os coordenadores declararam-se motivados também pelas contribuições que a extensão pode levar à sociedade: pela possibilidade de apresentar o turismo à sociedade, por pretender trabalhar pela melhoria da qualidade de vida das comunidades e pelo reconhecimento do 
compromisso da Universidade com a sociedade. Cabe destacar também que dois respondentes se referiram à indissociabilidade entre ensino, pesquisa e extensão como elementos motivadores, e um terceiro respondente chegou a indicar explicitamente o incentivo à pesquisa e à extensão por parte da instituição.

Solicitados a indicar os principais benefícios da extensão para a formação do egresso em Turismo, dez respondentes destacaram a chamada "integração teoria e prática" com vistas ao aprimoramento profissional. Cinco coordenadores também indicaram fatores relacionados ao desenvolvimento de senso de responsabilidade e o comprometimento com a sociedade. Notase também o entendimento da extensão como forma de o aluno desenvolver uma visão mais crítica da realidade, a partir da qual ele pode, inclusive, vislumbrar possibilidades de atuação conforme seus potenciais. Além desses aspectos, foram apontados benefícios referentes à aprendizagem do trabalho em equipe, à formação multi e interdisciplinar, ao contato com o trade e com o público, bem como a vivência universitária.

Observa-se, de modo geral, que os respondentes apresentam uma concepção de extensão como aplicação dos conteúdos trabalhados em sala de aula. Se por um lado tal entendimento destaca a importância das práticas extensionistas para uma formação global, conectada à sociedade, às comunidades e ao mercado de trabalho, por outro evidencia as colocações de Cunha (1998) acerta da ótica positivista que orienta o trabalho com o currículo nas Universidades e dificulta a integração entre ensino, pesquisa e extensão.

No caso dos benefícios para a instituição, 12 coordenadores fizeram referência à missão da Universidade de contribuir com a sociedade, exercendo seu "papel social" e "[...] devolvendo à sociedade o saber adquirido por seu corpo discente". O compromisso social é assim entendido como um benefício à Universidade. Isso se deve, possivelmente, à possibilidade de exposição positiva e consequente reconhecimento por parte da sociedade, como sugere uma das respostas: "[...] A comunidade passa a entender com maior profundidade o objetivo da universidade, respeitando- $a$, consequentemente." Alguns coordenadores mencionaram também benefícios relativos à construção do conhecimento e à formação dos discentes e docentes em razão da troca de experiências, da aproximação do conhecimento científico da realidade. 
No que tange à sociedade, os coordenadores aludiram, principalmente, a três grupos de benefícios, quais sejam, a aquisição ou construção de conhecimento, a melhoria das condições de vida e a promoção da cidadania, como explicitam os trechos a seguir.

A sociedade se beneficia com projetos que trazem conhecimento, entretenimento e se sente valorizada. Por outro lado, a comunidade estando próxima da universidade é estimulada a se qualificar e dá mais valor ao ensino.

Receber e ser beneficiada pela Universidade com os resultados das ações de ensino e pesquisa.

Que se beneficia dessas ações por ter pessoas que, especialistas em sua área, podem levar esse conhecimento pra fora dos muros da Universidade. Este, acredito, o verdadeiro sentido do ensino universitário: poder fazer cidadãos melhores para uma transformação social.

Receber orientação qualificada para as suas práticas cotidianas.

Um espaço para a busca de soluções e demandas das comunidades; um espaço para a qualificação profissional, para trocas e construção de conhecimentos e um veículo de comunicação entre sociedade $e$ Universidade.

Note-se que, em alguns casos, as palavras utilizadas revelam um entendimento da sociedade como paciente das ações extensionistas: na primeira citação, ela se beneficia de projetos que trazem conhecimento; na segunda e na quarta, recebe os resultados e orientações da Universidade; na terceira, é a Universidade que pode fazer cidadãos melhores. Por outro lado, na quinta, o respondente deixa transparecer um entendimento de extensão como construção coletiva de conhecimentos, como espaço de busca de soluções e comunicação.

Com o intuito de identificar o conceito de extensão que orienta as ações vinculadas, perguntou-se aos seus coordenadores como definiriam extensão universitária. As respostas podem ser organizadas em quatro grupos. O primeiro corresponde a 3 paráfrases da definição utilizada pelo Forproex (2000), na medida em que se referem à extensão como processo educativo, cultural e científico, fazem alusão à articulação entre ensino, pesquisa e extensão e citam a relação transformadora entre Universidade e sociedade.

O segundo grupo contempla, na realidade, 3 caracterizações da extensão insuficientes para conceituá-la, ainda que destaquem elementos que a constituem, como se observa nos 
seguintes depoimentos: "Como um dos pilares de sustentação do ensino superior." "Uma experiência fantástica! Vida além dos muros da universidade."

O terceiro grupo é o mais representativo e apresenta 7 definições que entendem a extensão como forma de a Universidade aproximar-se da sociedade, estendendo a ela os conhecimentos que produz e, eventualmente, coletando subsídios para produção de novos conhecimentos.

A oportunidade de devolver para a comunidade o conhecimento acumulado no intramuro das universidades. É a oportunidade de testar esse conhecimento e aproximar a comunidade da universidade.

Por fim, o quarto grupo abrange duas abordagens que, apesar de também conceituarem extensão como aproximação entre Universidade e sociedade e como retorno ou oferta do conhecimento produzido, admitem explicitamente o diálogo e a existência de um conhecimento produzido fora do ambiente acadêmico.

Um retorno que a Universidade, principalmente a pública e gratuita, deve dar a sociedade. Uma ação que aproxima o conhecimento acadêmico com o conhecimento popular e social, espaço de socialização e também veículo de aproximação ao acesso universitário.

A extensão universitária para mim é uma atividade de aproximação da universidade com a sociedade, onde ocorre uma relação de troca $e$ aprendizagem do conhecimento produzido por ambos. É também uma responsabilidade da universidade para com a sociedade no sentido de oferecer sua pesquisa e seu ensino para a sociedade.

Observa-se, de modo geral, nas respostas dos coordenadores, uma ênfase à extensão como realização do compromisso social da Universidade. Cabe lembrar, porém que, conforme Botomé (1996), o compromisso social deve ser realizado em todas as atividades universitárias, uma vez que a função de qualquer instituição social não é outra senão a de melhorar a qualidade de vida na sociedade.

Nota-se, também, em alguns casos, um entendimento da Universidade como a principal agente das transformações que a extensão pode ocasionar na sociedade, reforçando o que Freire (1993) já sinalizava como um caráter invasivo da prática extensionista, apenas 
estendendo saberes aos considerados menos favorecidos. Outros respondentes, porém, referem-se à extensão como espaço para trocas e diálogo, enfatizando a comunicação e a construção coletiva de conhecimentos em detrimento da transmissão e do estender de saberes (FREIRE, 1993).

Por fim, cabe comentar os conceitos de extensão implícitos não apenas nas definições de extensão apresentadas pelos coordenadores, mas em outros momentos do questionário, em que se observam elementos de diferentes momentos conceituais da extensão (SERRANO, 2008). A ideia de transmissão vertical do conhecimento, por exemplo, está implícita em trechos que destacam a extensão como forma de levar à sociedade os conhecimentos produzidos na Universidade e descrevem a sociedade como a receptora de tais conhecimentos. A ação sociocomunitária, por sua vez, se faz presente nas respostas que enfatizam o comprometimento da extensão com mudanças e transformações sociais que produzem melhorias na qualidade de vida. Já o momento acadêmico-institucional transparece não apenas nas definições que parafraseiam trechos da definição do Forproex (2000), mas nos trechos que destacam a troca e as possibilidades de a Universidade também se beneficiar a partir da relação com a sociedade.

\section{Considerações Finais}

Em decorrência da escolha do SIGProj como fonte de coleta de dados das ações extensionistas em Turismo, todas as ações descritas foram desenvolvidas por instituições de ensino superior públicas, especialmente federais, uma vez que essa base é de responsabilidade operacional do Ministério da Educação. Assim, os resultados obtidos não podem ser generalizados a todas as instituições de ensino superior do Brasil, incluindo as estaduais, municipais, privadas e comunitárias. No entanto, refletem um conjunto de ações extensionistas em universidades federais do país.

As ações extensionistas mostraram-se variadas, distribuídas por instituições das diferentes regiões do Brasil e relacionadas a diferentes áreas de conhecimento, com ênfase nas disciplinas das Ciências Humanas e Sociais. Entre as áreas temáticas, sobressaem-se Tecnologia e Produção, Direitos Humanos e Justiça, e Trabalho, sugerindo uma relação entre 
o turismo e desenvolvimento socioeconômico. Em que pesem as modalidades de ações, predominam os projetos, com mais de metade das ações identificadas, seguidos por eventos e cursos. A duração varia conforme a modalidade de ação; cursos e eventos costumam ser mais pontuais e ter durações reduzidas. Os projetos duram, em média, em torno de dez meses. O público-alvo das ações é igualmente variado, atingindo - como esperado - sobretudo a comunidade externa em seus diferentes segmentos: estudantes, membros de comunidades específicas ou do entorno das instituições, profissionais do setor, empresários, membros do governo, associações. Chama, porém, a atenção o fato de algumas ações voltarem-se exclusivamente aos graduandos das instituições em que se realizam, especialmente àquelas dirigidas, sobretudo, a bacharelandos em Turismo.

A pesquisa permitiu também identificar a concepção de extensão na visão dos coordenadores das ações extensionistas vinculadas a cursos de Turismo. Primeiramente, a extensão é entendida como forma de a Universidade realizar seu compromisso social, por meio do compartilhar de conhecimentos produzidos e de intervenções que possibilitem melhorar a qualidade de vida do público atendido. No que diz respeito aos graduandos participantes das ações, a extensão é vista, especialmente, como forma de aplicar os conhecimentos teóricos de sala de aula e unir teoria e prática, além de constituir uma experiência que pode ampliar a consciência crítica dos envolvidos e seu senso de responsabilidade social. Note-se, uma vez mais, a extensão associada ao compromisso social da Universidade, o que pode gerar uma visão equivocada de que as ações extensionistas expiariam as instituições de ensino das alienações produzidas no âmbito da pesquisa e do ensino. Outro conceito presente é o de extensão como pilar da Universidade - pesquisa e ensino seriam os outros dois. Embora isso possa configurar apenas reflexo da terminologia comumente utilizada e da imagem associada à extensão, é importante atentar para as implicações que dela podem decorrer. Entender cada pilar como elemento essencial para sustentação e equilíbrio do tripé vai ao encontro da indissociabilidade; entretanto, se a perspectiva que se tem é de elementos independentes a imagem pode reforçar o isolamento das três dimensões do ensino superior.

Os resultados obtidos nesta pesquisa permitem compreender como a extensão universitária em Turismo é praticada e compreendida no âmbito das instituições públicas brasileiras. Ao contrário do que a ausência de dissertações e teses sobre o tema poderia sugerir, há sim ações 
extensionistas voltadas a problemáticas do turismo, realizadas não apenas no âmbito dos bacharelados nesta área, mas em diferentes departamentos. Ainda que alguns coordenadores refiram-se a conceitos controversos sobre a extensão, nota-se também uma compreensão abrangente dos benefícios da extensão para todos os envolvidos.

Acredita-se que os resultados aqui apresentados possam trazer contribuições relevantes e significativas para a compreensão da extensão universitária em Turismo, ampliando suas perspectivas e possibilidades, e despertando o interesse de outros pesquisadores para o estudo do tema. Ao mesmo tempo, tomando-se conhecimento de projetos e ações de extensão na área, poder-se-á contribuir para o seu estímulo e aprimoramento junto aos cursos de Turismo vinculados ao ensino e à pesquisa nos mesmos.

\section{Referências}

ANSARAH, Marília Gomes dos Reis; REJOWSKI, Mirian. Panorama de ensino em turismo no Brasil - graduação e pós-graduação. Turismo em Análise, São Paulo, v. 7, n. 1, p. 36-61, 1996.

BARRETTO, Margarita; TAMANINI, Elizabeth; SILVA, Maria Ivonete Pereira da. Discutindo o ensino universitário de turismo. Campinas: Papirus, 2004.

BOTOMÉ, Silvio Paulo. Extensão Universitária: equívocos, exigências, prioridades e perspectivas para a universidade. In: FARIA, Dóris Santos de (Org.). Construção conceitual de extensão universitária na América Latina. Brasília: UnB, 2001. p.159-175. Vozes, 1996.

Pesquisa alienada, ensino alienante: o equívoco da extensão universitária. Petropólis, RJ:

BRASIL. Decreto n. 19.851, de 11 de abril de 1931. Estabelece o Estatuto das Universidades Brasileiras. Disponível em: <http://www2.camara.gov.br/legin/fed/decret/1930-1939/decreto-1985111-abril-1931-505837-publicacaooriginal-1-pe.html>. Acesso em: 12 dez.2011.

Lei n.9.394, de 20 dez. 1996. Lei de Diretrizes e Bases da Educação. Disponível em: <http://www.planalto.gov.br/ccivil_03/leis/L9394.htm>. Acesso em: 10 dez. 2011.

. Ministério da Educação. Plano Plurianual 2000-2003.Brasília: MEC, 1999.

CARBONARI, Maria Elisa Ehrhardt; PEREIRA, Adriana Camargo. A extensão universitária no Brasil, do assistencialismo à sustentabilidade. Revista de Educação, v. 10, n.10, p.23-28, 2007.

CARVALHO, Mariana Aldrigui. Os números do ensino superior em turismo e hospitalidade no Brasil - 2001 a 2006. In: SEMINÁRIO DA ASSOCIAÇÃO NACIONAL PESQUISA E PÓSGRADUAÇÃO EM TURISMO, 5., Belo Horizonte, MG. Anais... Belo Horizonte,BH: Anptur, 2008.

CUNHA, Maria Isabel da. Aportes teóricos e reflexão da prática: A emergente reconfigurção dos currículos universitários. Educación superior y sociedade, Unesco/Venezuela, v.9, n.1, p.11-20, 1998. 
Indicadores de qualidade e a relação do ensino com a pesquisa e a extensão na universidade brasileira. In: COLOQUIO INTERNACIONAL SOBRE GESTIÓN UNIVERSITARIA EN AMÉRICA DEL SUR, 10, 2010. Mar del Plata, Argentina. Anais...Mar del Plata, Argentinha: 2010.

DENCKER, Ada de Freitas Maneti. Pesquisa em Turismo: planejamento, métodos e técnicas. São Paulo: Futura, 2007.

FORPROEX (Fórum dos Pró-reitores de Extensão das Universidade Públicas Brasileiras). Avaliação nacional da extensão universitária. Brasília: MEC/SESU, 2001.

. Extensão universitária: organização e sistematização. Belo Horizonte: COOPMED, 2007a.

Institucionalização da extensão nas universidades públicas brasileiras: estudo comparativo 1993/2004. 2.ed. Belo Horizonte: COOPMED, 2007 b.

Plano nacional de extensão universitária: edição atualizada. Brasília, DF: Forproex / $\overline{\mathrm{MEC} / \mathrm{SESu}} 2000$.

Política Nacional de Extensão Universitária. Manaus, AM: Forproex, 2012.

FREIRE, Paulo. Extensão ou comunicação. 13. ed. São Paulo: Paz e Terra, 1983.

GURGEL, Roberto Mauro. Extensão universitária: comunicação ou domesticação. São Paulo: Cortez/EUFC/Autores associados, 1986.

JAFARI, Jafar. El turismo como disciplina científica. Política y sociedade, Madrid, Espanha, v. 42, n. 1, p. 39-56, 2005.

MALERBA, Rafaela Camara; LANDI, Camila de Meirelles; REJOWSKI, Mirian. Extensão universitária em turismo no Brasil: mapeamento preliminar. In: Seminário da Associação Nacional Pesquisa e Pós-Graduação em Turismo, 8., Balneário Camboriú, SC. Anais... Balneário Camboriú, SC: Anptur, 2011.

MEC (Ministério da Educação). Secretaria de Educação Superior. Sistema de Informação e Gestão de Projetos - SIGProj. Disponível em: 〈http://sigproj1.mec.gov.br〉. Acesso em: 10 maio 2012.

NOGUEIRA, Maria das Dores Pimentel. Extensão universitária no Brasil: uma revisão conceitual. In: FARIA, Dóris Santos de (Org.). Construção conceitual da extensão universitária na América Latina. Brasília: Universidade de Brasília, 2001. p.57-72.

OLIVEIRA, Alcivan Paulo. O Forext: uma perspectiva histórica. In: A extensão nas universidades e instituições de ensino superior comunitárias: referenciais teórico e metodológico. FOREXT, 2006. p. 3-8. Disponível em: <http://www.metodista.br/ev/forext/ ForExt\%20historia.pdf>. Acesso em: 10 maio 2012.

PANOSSO NETTO. Filosofia do Turismo: teoria e epistemologia. 2. ed. São Paulo: Aleph, 2011.

REJOWSKI, M. Turismo e pesquisa científica: pensamento internacional versus realidade brasileira. Campinas: Papirus, 1996.

. Ensino e pesquisa em turismo e hospitalidade: disciplina do mestrado em Hospitalidade. 15 mar. a 15 jun. de 2011. Notas de aula.

Pesquisa científica em turismo no Brasil: comunicação, produtividade e posicionamento. São Paulo: UAM, 2010 (Relatório de pesquisa CNPq).

RENEX (Rede Nacional de Extensão). Política nacional de extensão - áreas temáticas. Disponível em: $\quad<\mathrm{http}: / / \mathrm{www} \cdot$.renex.org.br/index.php?option=com_content\&view=article\&id $=2 \&$ Itemid $=3>$. Acesso em: 2 jun. 2011. 
ROCHA, José Cláudio. A reinvenção solidária e participativa da universidade: um estudo de caso múltiplo sobre rede de extensão universitária no Brasil. 2006. 323 f. Tese (Doutorado em Educação). Universidade Federal da Bahia (UFBA), Salvador, 2006.

ROCHA, Roberto Mauro Gurgel. A construção do conceito de extensão universitária na América Latina. In: FARIA, Dóris Santos de (Org.). Construção conceitual da extensão universitária na América Latina. Brasília: Universidade de Brasília, 2001. p.13-30.

SERRANO, Rosana Maria Souto Maior. Conceitos de extensão universitária: um diálogo com Paulo Freire. 2008. Extelar Grupo de pesquisa em extensão popular. Disponível em: $<$ http://www.prac.ufpb.br/copac/extelar/atividades/discussao/artigos/conceitos_de_extensao_universit aria.pdf >. Acesso em: 25 abr. 2011.

SOUSA, Ana Luisa Lima. A história da extensão universitária. 2.ed. Campinas, SP: Alínea, 2010.

Concepção de extensão universitária: ainda precisamos falar sobre isso? In: FARIA, Dóris Santos de (Org.). Construção conceitual da extensão universitária na América Latina. Brasília: Universidade de Brasília, 2001. p.107-126.

SHIGUNOV NETO, A. MACIEL, L. S. B. Currículo e formação profissional nos cursos de Turismo. Campinas: Papirus, 2002.

SOUZA, João Carlos; BORTOLINI, Maristela Helena Zimmer; NODARI, Eunice Sueli. Extensão Universitária da UFSC/Brasil: processos de avaliação e apoio financeiro. Coloquio Internacional sobre Gestion Universitaria en America Del Sur: movillidad, governabilidad e integración regional (7). Anais... Mar Del Plata, Argentina, 2007.

THIOLLENT, Michel Jean-Marie. Avanços da metodologia e da participação na extensão universitária. In: ARAÚJO FILHO, Targino; THIOLLENT, Michel Jean-Marie. Metodologia para projetos de extensão: apresentação e discussão. São Carlos, SP: Cubo Multimídia, 2008.

TRIBE, John. The indiscipline of tourim. Annals of Tourism Research, v. 24, n.3, p.638-657, 1997. Disponível em: <http://www.sciencedirect.com/science/article/pii/S01607383050 00666>. Acesso em: 14 jan. 2012.

Pesquisa, conhecimento e currículo. In: AIREY, David; TRIBE, Jonh. Educação internacional em turismo. São Paulo: Senac, 2008.

Recebido em: $22 / 11 / 2012$ ( $1^{\mathrm{a}}$ versão) $04 / 11 / 2013$ ( $2^{\mathrm{a}}$ versão)

Aprovado em: 12/03/2014 